\title{
ON SOME GRONWALL TYPE INEQUALITIES INVOLVING ITERATED INTEGRALS
}

\author{
Yeol Je Cho, Sever S. Dragomir and Young-Ho Kim
}

Abstract. In this paper we consider simple inequalities involving iterated integrals in the inequality (1.1) for functions when the function $u$ in the both side of the inequality (1.1) are replaced by the function $w(u)$ and $\varphi(u)$ for some functions $w, \varphi$ and provide some retarded integral inequalities involving iterated integrals. Some applications are also given to illustrate the usefulness of our results.

Mathematics subject classification (2010): 26D15, 35A05.

Keywords and phrases: Gronwall-Bellman inequalities, retarded integral inequalities, iterated integrals, integro-differential equation.

\section{REFERENCES}

[1] D. Bainov and P. Simeonov, Integral Inequalities and Applications, Kluwer Academic Publishers, Dordrecht, 1992.

[2] R. Bellman, The stability of solutions of linear differential equations, Duke Math. J., 10 (1943), 643-647.

[3] I. BIHARI, A generalization of a lemma of Bellman and its application to uniqueness problems of differential equations, Acta. Math. Acad. Sci. Hungar., 7 (1956), 71-94.

[4] W. S. CheUnG, Some new nonlinear inequalities and applications to boundary value problems, Nonlinear Anal., 64 (2006), 2112-2128.

[5] W. S. Cheung AND Q. H. MA, On certain new Gronwall-Qu-Iang type integral inequalities in two variables and their applications, J. Inequali. Appl., 4 (2005), 347-361.

[6] Y. J. Cho, S. S. DraGomiR AND Y.-H. Kim, On some integral ineualities with iterated integrals, J. Korean Math. Soc., 43 (2006), 563-578.

[7] S. S. Dragomir And Y.-H. Kim, On certain new integral inequalities and their applications, J. Inequal. Pure Appl. Math., 3 (2002), Artical 65, http: / j i ipam.vu.edu.au/.

[8] T. H. Gronwall, Note on the derivatives with respect to a parameter of solutions of a system of differential equations, Ann. Math., 20 (1919), 292-296.

[9] L. Guiliano, Generalazzioni di un lemma di Gronwall, Rend. Accad., Lincei (1946), 1264-1271.

[10] C. E. LANGENHOP, Bounds on the norm of a solution of a general differential equation, Proc. Amer. Math. Soc., 11 (1960), 795-799.

[11] O. Lipovan, A retarded integral inequality and its applications, J. Math. Anal. Appl., 285 (2003), 336-443.

[12] V. V. Nemyckit and V. V. Stepanov, Qualitative theory of differential equations (Russian), Moscow, OGIZ (1947).

[13] B. G. PAChPATtE, Inequalities for Differential and Integral Equations, Academic Press, New York, 1998.

[14] B. G. PachPatte, Explicit bounds on certain integral inequalities, J. Math. Anal. Appl., 267 (2002), $48-61$.

[15] B. G. PAChPatte, On a certain retarded integral inequality and applications, J. Inequal. Pure and Appl. Math., 5, 1 (2004), Art. 19, http://jipam.vu.edu.au/.

[16] B. G. PachPatte, On some new nonlinear retarded integral inequalities, J. Inequal. Pure and Appl. Math., 5, 3 (2004), Art. 80, http://jipam.vu.edu.au/. 
[17] X. Zhao and F. Meng, On some advanced integral inequalities and their applications, J. Inequal. Pure and Appl. Math., 6, 3 (2005), Art. 60, http: //jipam.vu.edu.au/.

[18] H. YE, J. GAO AND Y. DiNG, A generalized Gronwall inequality and its application to a fractional differential equation, J. Math. Anal. Appl., 328, 2 (2007), 1075-1081. 